\title{
Estimation of Lipid Profiles of Patients with Type-2 Diabetes Mellitus at Adoor, Kerala
}

\author{
P. Leela Kumari ${ }^{\odot}$ \\ Associate Professor, Department of General Medicine, Mount Zion Medical College Hospital Ezhamkulam, Adoor, Pathanamthitta, Kerala, India.
}

\section{Abstract}

Background: Lipid abnormalities in patients with diabetes are often phrased as "diabetic dyslipidemia". The aim of the study was to evaluate the lipid profiles of patients with type-2 diabetes mellitus. Subjects and Methods: the subjects who were enrolled in this study were diabetic patients. For the study, a total of 150 diabetic patients with a history of diabetes for 10 years were arbitrarily chosen and scrutinized for dyslipidemia. Patients with other diseases and metabolic disarray were barred from the study. The patients were selected on an indiscriminate base and detailed case history was measured with all appropriate clinical checks. Results: Total 140 diabetic patients with a mean age of $49.98 \pm 13.3$ years were included in the study. The mean FBS of study participants was $189.78 \pm 55.65 \mathrm{mg} / \mathrm{dl}$. Mean triglycerides level was $203.59 \pm 84.48 \mathrm{mg} / \mathrm{dl}$. Out of the total 150 patients, borderline high cholesterol (200-239 mg/dl) and high cholesterol ( $\geq 240 \mathrm{mg} / \mathrm{dl})$ level were $29(19.3 \%)$ and $22(14.6 \%)$ respectively. Out of 150 subjects, 37(24.6\%) had borderline high triglyceride (150-199 mg/dl) while 61 (40.6\%) had high triglyceride (200-249 $\mathrm{mg} / \mathrm{dl})$ level. Conclusion: Hyperlipidemia is the most frequent snag of diabetes mellitus and it can prompt patients to precipitate atherosclerosis and microvascular difficulty. Good glycemic control can avert the advances and succession of usual lipid irregularity in diabetes like heightened triglycerides, LDL, serum cholesterol and low HDL.

Keywords: Hyperlipidemia, Glycemic Control, Diabetic Dyslipidemia, Diabetes Mellitus

Corresponding Author: P. Leela Kumari, Associate Professor, Department of General Medicine, Mount Zion Medical College Hospital Ezhamkulam, Adoor, Pathanamthitta, Kerala, India.

E-mail: leelakumari9@yahoo.com

Received: 26 September 2020

Revised: 15 November 2020

Accepted: 26 November 2020

Published: 26 December 2020

\section{Introduction}

Diabetes mellitus is marked as a heterogeneous group of metabolic disorders. It is exemplified by hyperglycemia with interruptions of carbohydrate, fat and protein metabolism rooted by either being short in insulin discharge or lessened sensitivity of tissues to insulin. ${ }^{[1,2]}$ Worldwide, diabetes mellitus is considered to be one of the most ubiquitous noncommunicable ailments. The mounting numbers of diabetes mellitus are very distressing. It has been estimated more than 175 million all across the globe. The numbers of diabetic sufferers have risen worldwide and its pervasiveness has been intensifying more speedily in middle and low-income nations. ${ }^{[3]}$ Sadly, India leads the globe with the highest numbers of diabetic sufferers and is often referred to as the diabetes capital of the world, ${ }^{[4]}$ with a predictable 109 million populace with diabetes by the end of the year 2035. At present, the ailment is currently affecting more than 62 million populace of the nation which is about $7.2 \%$ of India's adult populace. ${ }^{[5,6]}$ Lipid abnormalities in patients with dia- betes are often phrased as "diabetic dyslipidemia". It is characteristically exemplified by high total cholesterol (T-Chol), high triglycerides (Tg), low high-density lipoprotein cholesterol (HDL-C) and augmented levels of small dense LDL particles. Low-density lipoprotein cholesterol (LDL-C) levels may be reasonably amplified or ordinary. Lipid abnormalities are frequent in people with T2DM and pre diabetes, ${ }^{[7,8]}$ however, the prototype of diverse lipids may fluctuate between ethnic groups, economic levels, and access to health care. ${ }^{[9,10]}$ It is customary that dyslipidemia is a foremost menace factor for a macrovascular obstacle in patients with type-2 diabetes mellitus (T2DM) and influences 10\%-73\% of inhabitants.In unrestrained diabetes, serum triglycerides, Very Low-Density Lipoproteins (VLDL), cholesterol are elevated at fasting \& following a fixed meal. In post mixed meal Chylomicrons remnants \& Low-Density Lipoproteins (LDL) stays lofty for longer than normal. Total cholesterol \& LDL are mild to moderate high in $1 / 3$ patients. On the other end, HDL lingers drastically low predominantly in type-2 diabetes patients with central obesity. Among modifications in the composition of 
Lipoproteins high proportion of small, dense triglyceride-rich LDL \& glycoxidation products of LDL are measured to be most atherogenic. The age-adjusted occurrence of coronary artery ailment is 3 to 5 times advanced in male \& female diabetics as paralleled to general residents. Persons with diabetes may have numerous appearances of dyslipidemia mounting to additive cardiovascular jeopardy of hyperglycemia. So, lipid abnormalities should be uncompromisingly noticed \& dealt with as a part of inclusive diabetic heed.Insulin deficit grounds extreme metabolization of complimentary fatty acids. This may advance to disarray in lipid metabolism. Insulin is a hypoglycemic hormone oozed from $\beta$-cell of the islet of the pancreas. Insulin also has an influence on lipid metabolism. ${ }^{[11]}$ The validation of the current work was to assess lipid aberration in diabetic patients. Timely uncovering and management of hyperlipidemia in diabetes mellitus can thwart the succession of lipid abnormalities and can also lessen the peril for atherogenic cardiovascular muddle and cerebrovascular accidents. Therefore, the intention of this work was to examine the lipid profile in type 2 diabetes mellitus patients.

\section{Subjects and Methods}

The study was carried out at the Medicine Department in subjects who were diabetic patients. For the study, a total of 150 diabetic patients with a history of diabetes for 10 years were arbitrarily chosen and scrutinized for dyslipidemia. Patients with other diseases and metabolic disarray were barred from the study. The patients were selected on an indiscriminate base and detailed case history was measured with all appropriate clinical checks. Furthermore, regular examinations were performed. Authorization from the ethical committee was obtained prior to the beginning of the work. Moreover, informed sanctions were sought from all the contributors. Each patient was counseled for at least 12 to 14 hours. Overnight fasting and $5 \mathrm{ml}$ of venous blood tasters were collected in a not reusable syringe the next morning (before breakfast) for the serum lipid profile and fasting blood. The lipid profiles were calculated. The acknowledged cases of type 2 diabetes mellitus will also be assessed for their blood sugar (control or un-control) by counseling the HbA1C level. Attained data were examined by using the Statistical Package of Social Sciences (SPSS-IBM) version 22.0. Descriptive statistics were computed for the variables. The connection between variables was scrutinized by means of chi-square tests. The connection of variables was noteworthy it the pvalue was less than or equivalent to 0.05 .

\section{Results}

[Table -1$]$ shows mean age, fasting blood sugar and mean values of various lipid profile parameters. Total 150 diabetic patients with a mean age of $49.98 \pm 13.3$ years were included in the study. The mean FBS of study participants was $189.78 \pm 55.65 \mathrm{mg} / \mathrm{dl}$. Mean triglycerides level was $203.59 \pm$ $84.48 \mathrm{mg} / \mathrm{dl}$.

Table 1: Mean values of biochemical parameters of Diabetic patients $(\mathrm{n}=150)$.

\begin{tabular}{ll}
\hline Parameters & Mean \pm SD \\
\hline Age $($ years $)$ & $49.98 \pm 13.3$ \\
\hline FBS $(\mathrm{mg} / \mathrm{dl})$ & $189.78 \pm 55.65$ \\
Total cholesterol $(\mathrm{mg} / \mathrm{dl})$ & $188.25 \pm 37.21$ \\
Triglycerides $(\mathrm{mg} / \mathrm{dl})$ & $203.59 \pm 84.48$ \\
HDL-C $(\mathrm{mg} / \mathrm{dl})$ & $36.19 \pm 5.61$ \\
LDL-C $(\mathrm{mg} / \mathrm{dl})$ & $119.49 \pm 39.92$ \\
\hline
\end{tabular}

[Table - 2] shows the distribution of study subjects according to the Adult Treatment Panel III (ATP III) classification. Out of the total 150 patients, borderline high cholesterol (200$239 \mathrm{mg} / \mathrm{dl})$ and high cholesterol $(\geq 240 \mathrm{mg} / \mathrm{dl})$ level were 29 $(19.3 \%)$ and $22(14.6 \%)$ respectively. Out of 150 subjects, $37(24.6 \%)$ had borderline high triglyceride $(150-199 \mathrm{mg} / \mathrm{dl})$ while 61 (40.6\%) had high triglyceride (200-249 mg/dl) level.

Table 2: Distribution of Biochemical parameters according to ATP III classification.

\begin{tabular}{|ll|}
\hline Total cholesterol (mg/dl) & \\
Desirable $(<200)$ & $99(66 \%)$ \\
\hline Borderline high $(200-239)$ & $29(19.3 \%)$ \\
\hline High $(\geq 240)$ & $22(14.6 \%)$ \\
\hline Triglycerides (mg/dl) & \\
\hline Normal $(<150)$ & $52(34.6 \%)$ \\
\hline Borderline high $(150-199)$ & $37(24.6 \%)$ \\
\hline High $(200-249)$ & $61(40.6 \%)$ \\
\hline HDL-C $(\mathrm{mg} / \mathrm{dl})$ & \\
\hline Low $(<40)$ & $105(70 \%)$ \\
Borderline high $(40-59)$ & $38(25.3 \%)$ \\
\hline High $(\geq 60)$ & $7(4.6 \%)$ \\
\hline LDL-C $(\mathrm{mg} / \mathrm{dl})$ & \\
Optimal $(<100)$ & $55(36.6 \%)$ \\
\hline Near optimal $(100-129)$ & $45(30 \%)$ \\
\hline Borderline high $(130-159)$ & $27(18 \%)$ \\
\hline High $(160-189)$ & $14(9.3 \%)$ \\
\hline Very high $(\geq 190)$ & $9(6 \%)$ \\
\hline
\end{tabular}




\section{Discussion}

Patients with diabetes have been evidently recognized with arising complications owing to the unceasing hyperglycemia that wields its injurious to health all the way through numerous mechanisms like dyslipidemia, platelet activation, and altered endothelial metabolism. ${ }^{[12,13]}$ Both lipid profile and diabetes have been revealed to be the imperative forecasters for metabolic commotions encompassing dyslipidemia, hypertension and cardiovascular ailments. ${ }^{[14]}$ Lipids are very vital in the pathogenesis of diabetes mellitus. Dyslipidemia as a metabolic aberration is recurrently connected with diabetes mellitus. Idiosyncrasy in lipid metabolism has been accounted for in sufferers with diabetes mellitus attended with the peril of cardiovascular arteriosclerosis. ${ }^{[15]}$ In current work, considerably elevated mean serum levels of total cholesterol, triglycerides and LDL cholesterol were figured out in patients with diabetes, which are well-identified menace causes for cardiovascular ailments amidst patients when measured with normal values. Usually, free radicals created in metabolism efficiently forage. Oxidative stress roots when there is an inequity between creations and scavenge. Augmented in lipid peroxidation in diabetes mellitus is because of the surplus configuration of free radicals. Glycosylated protein, autooxidation, reduced superoxide dismutase enzyme and ascorbic acid and scarcity of condensed glutathione are supplementary reasons for oxidative strain. ${ }^{[15]}$ There are two key types of diabetes, ${ }^{[16]}$ Insulin-dependent diabetes (Type 1 Diabetes). ${ }^{[16]}$ It happens when there is a stern deficiency of insulin due to the obliteration of most or all of the beta cells in the islets of Langerhans. This type of diabetes expands swiftly, typically emerging before the age of 35 , and most frequently between the ages of 10 and 16. Regular insulin injections are required to sustain. Non-insulin-dependent diabetes (type 2 diabetes). ${ }^{[16]}$ It originates when the body does not make adequate insulin, and the insulin that is formed turns less efficient. These types of diabetes typically emerge in a populace over the age of 40 , and tend to have a more gradual onset. In most cases, glucose levels in the blood can be proscribed by diet, or diet and tablets, though, at times, insulin injections may be required. About 90 percent of diabetics are non-insulin reliant. ${ }^{[16]}$ The pervasiveness rates for high LDL-C, very high LDL-C and low HDL-C in the diabetic subjects. The type of dyslipidemia counted among the diabetic populace is frequent in dissimilar places in world representation that dyslipidemia can be predisposed by the dealings of genetic and environmental reasons. The predominance of the lipid anomaly accounted by Mexican countrywide investigation done by Carlos, et al, ${ }^{[17]}$ and other Asian populations, counting Bangladeshi and Pakistani nationals, ${ }^{[18]}$ displayed that about half of the diabetic inhabitants had hypertriglyceridemia. This work is in accord with the above-stated report in correlation to occurrence rates of hypertriglyceridemia among type 2 diabetic residents.

\section{Conclusion}

The diabetic patients had lofty serum total cholesterol, heightened triglyceride (triacylglycerol) and somewhat high lowdensity lipoprotein (LDL-C) and abridged levels of highdensity lipoprotein (HDL-C) demonstrating that diabetic patients were more prone to cardiovascular ailments. Hyperlipidemia is the most frequent snag of diabetes mellitus and it can prompt patients to precipitate atherosclerosis and microvascular difficulty. Good glycemic control can avert the advances and succession of usual lipid irregularity in diabetes like heightened triglycerides, LDL, serum cholesterol and low HDL.

\section{References}

1. Rossi G. Diagnosis and classification of diabetes mellitus.Recent progress in medicine; 2010.

2. Guyton AC, Hall JE; 2013.

3. Diagnosis and classification of diabetes mellitus. Dia Care. 2014;37(1):81-90. Available from: https://doi.org/10.2337/ dc14-S081.

4. Mooradian AD. Dyslipidemia in type 2 diabetes mellitus. Nat Rev Endocrinol . 2009;5(3):150-159. Available from: https: //dx.doi.org/10.1038/ncpendmet1066.

5. Ambrishmithal D, Shunmugavelu M, Talwarkar PG, Hardikvasnawala AS, Raza. Prevalence of dyslipidemia in adult Indian diabetic patients: A cross-sectional study (SOLID). Indian J Endocr Metab. 2014;18(5):642-647. Available from: https: //doi.org/10.4103/2230-8210.139220.

6. Chetanashenoy MM, Shenoy GK, Rao. Dyslipidemia in Dermatological Disorders. N Am J Med Sci. 2015;7(10):421428. Available from: https://dx.doi.org/10.4103/1947-2714. 168657.

7. Guariguata L, Whiting DR, Hambleton I, Beagley J, Linnenkamp U, Shaw JE. Global estimates of diabetes prevalence for 2013 and projections for 2035; 2014. Available from: https://dx.doi.org/10.1016/j.diabres.2013.11.002.

8. Santos-Gallego CG, Rosenson RS. Role of HDL in Those with Diabetes. Curr Cardiol Rep. 2014;16(9). Available from: https://dx.doi.org/10.1007/s11886-014-0512-5.

9. Gerber PA, Spirk D, Brändle M, Thoenes M, Lehmann R, Keller U. Regional differences of glycaemic control in patients with type 2 diabetes mellitus in Switzerland: a national crosssectional survey. Swiss Med Wkly. 2011;141. Available from: https://dx.doi.org/10.4414/smw.2011.13218.

10. Joshi SR, Anjana RM, Deepa M, Pradeepa R, Bhansali A, Dhandania VK. Prevalence of dyslipidemia in urban and rural India: The ICMR-INDIAN study. PLoS One. 2014;9(5):1-5. Available from: https://doi.org/10.1371/journal.pone.0096808.

11. Smith S, Lall AM. A Study on Lipid Profile Levels of Diabetics and Non- Diabetics AmongNaini Region of Allahabad, India. Turk J Biochem. 2008;33(4):138-141.

12. Taskinen MR. Diabetic dyslipidaemia: from basic research to clinical practice*. Diabetologia. 2003;46(6):733-749. 
Available from: https://dx.doi.org/10.1007/s00125-003-1111y.

13. Goldberg IJ. Diabetic dyslipidemia: causes and consequences. J Clin Endocr Metab. 2001;8(3):965-971. Available from: https://doi.org/10.1210/jcem.86.3.7304.

14. Krauss RM. Lipids and Lipoproteins in Patients With Type 2 Diabetes. Dia Care. 2004;27(6):1496-1504. Available from: https://dx.doi.org/10.2337/diacare.27.6.1496.

15. Smith S, Lall AM. A Study on Lipid Profile Levels of Diabetics and Non- Diabetics AmongNaini Region of Allahabad, India. Turk J Biochem. 2008;33(4):138-141.

16. Chatterjee MN, Shinde R. Textbook of medical laboratory technology. Metabolism of carbohydrates.(Jaypee Brothers Medical publisher )Sixth edition s. 266-330. Delhi-India; 2005.

17. Carlos A, Aguilar S, Gustavo O. High prevalence of low HDL cholesterol concentrations and mixed hyperlipidemia in a Mexican nationwide survey. J Lipid Res. 2001;42:1298-307.

18. Bhopal R, Unwin N, White M, Yallop J, Walker L, Alberti KGMM. Heterogeneity of coronary heart disease risk factors in Indian, Pakistani, Bangladeshi, and European origin populations: cross sectional study. BMJ. 1999;319(7204):215220. Available from: https://dx.doi.org/10.1136/bmj.319.7204. 215.

Copyright: (C) the author(s), 2020. It is an open-access article distributed under the terms of the Creative Commons Attribution License (CC BY 4.0), which permits authors to retain ownership of the copyright for their content, and allow anyone to download, reuse, reprint, modify, distribute and/or copy the content as long as the original authors and source are cited.

How to cite this article: Kumari PL. Estimation of Lipid Profiles of Patients with Type-2 Diabetes Mellitus at Adoor, Kerala. Acad. J Med. 2020;3(2):6-9.

DOI: dx.doi.org/10.47008/ajm.2020.3.2.2

Source of Support: Nil, Conflict of Interest: None declared. 